
$\mathbf{R}_{\text {ESEARCH }} \mathbf{P}_{\text {APER }} \longrightarrow$ FOOD SCIENCE

\title{
Dietary intake of primary school children among two tribes of Meghalaya
}

\author{
Namita Singh, Shipra Nagar and Ranjita Devi Takhellambam
}

\begin{abstract}
Mothers of selected primary school children of two tribes (Garo and Khasi) were personally contacted in their family and asked to provide necessary information for the researcher. The information were collected by using pre-structured deign interview schedule. Varied nutritional deficiency such as riboflavin, thiamine, Vitamin C and D and iron were observed in study subjects of both the tribes of Meghalaya. However, the study revealed that clinically there was no Vitamin A deficiency among the respondents even though the Vitamin A intake in terms of carotene is very low when compared to RDA. And there was no single case of folic acid and iodine deficiency observed among the study subject. Other than protein intake of other nutrients like energy, fat, iron, Ascorbic acid and carotene was lower than the RDA in all age group. Hence, the nutritional status of primary school children of two tribes of Meghalaya was not satisfactory.
\end{abstract}

Key Words : East Khasis, West Garo, Dietary intake, Ascorbic acid, Carotene

How to cite this article : Singh, Namita, Nagar, Shipra and Takhellambam, Ranjita Devi (2018). Dietary intake of primary school children among two tribes of Meghalaya. Food Sci. Res. J., 9(1): 88-93, DOI : 10.15740/HAS/FSRJ/9.1/88-93.

Ranjita Devi Takhellambam, Department of Food Science and Nutrition, College of Home Science, Central Agricultural University, Tura (Meghalaya) India 